\title{
Clinical, Biological and Ct Predictors of In-Hospital Mortality in Ischemic Stroke Patients in Central Africa
}

Michel Lelo Tshikwela ${ }^{1 *}$, Gloria Bugugu Cinama ${ }^{1}$, Stéphane Yanda Tongo ${ }^{1}$ Emmanuel Ndoma Kabu ${ }^{1}$, Fabien Kintoki Mbala², François Lepira Bompeka $^{3}$ and Euletère Kintoki Vita ${ }^{2}$

${ }^{1}$ Department of Radiology, Kinshasa University School of Medicine and Hospital, Kinshasa, Democratic Republic of the Congo

${ }^{2}$ Department of Internal Medicine, Unit of Cardiology, Kinshasa University School of Medicine and Hospital, Kinshasa, Democratic Republic of the Congo

${ }^{3}$ Department of Internal Medicine, Unit of Nephrology, Kinshasa University School of Medicine and Hospital, Kinshasa, Democratic Republic of the Congo

\section{Abstract}

Background: Stroke a major public health problem, its management remains a challenge for the medical professionals. We investigated the clinical, simple biological and tomographic determinants of outcome in patients suffering of ischemic stroke.

Materials and methods: This prospective study was conducted at Kinshasa university hospital from January 2011 to June 2014. A total of 104 consecutive patients with first-ever ischemic stroke confirmed by computed tomography examination were enrolled for the study. The parameters of interest were clinical, routine biochemical and radiological data within the 3 first days of symptom onset. Logistic regression was used to identify independent determinants of mortality risk.

Results: The average age of patients was $62 \pm 14$ years old with $68 \%$ of male. Among the 22 patients $(21 \%)$ who died, in univariate analysis, factors associated with lethality were the Glasgow score $<9$, higher elevated erythrocyte sedimentation rate $>40 \mathrm{~mm} / 1 \mathrm{~h}$, higher leukocytosis $>10.000$ elements $/ \mathrm{mm} 3$ and non-lacunar brain infarct. On multiple logistic regression analysis, higher elevated erythrocyte sedimentation rate (OR 1.8; 95\% Cl 1.22 to $89.35 ; p=0.032)$, lesion located in infra-tentorial area (OR $4.7 ; 95 \% \mathrm{Cl} 1.30$ to $16.38 ; p=0.017)$ and hemorrhagic infarct (OR $10.6 ; 95 \%$ $\mathrm{Cl} 2.21$ to $77.89 ; \mathrm{p}=0.005$ ) were essentially independent determinants of ischemic stroke mortality.

Conclusion: The study seems to determine factors associated with mortality in patients suffering from cerebral infarction. Glasgow score and routine biomarkers may be useful in low setting area to assess mortality in ischemic stroke patient.

Keywords: Ischemic stroke; Predictors of mortality; Central Africa

\section{Introduction}

Stroke is a leading cause of mortality and a long-term disability with an enormous economic burden by over the world [1-3] and Democratic Republic of the Congo (DRC), where chronic hypertension, diabetes mellitus, heavy alcohol consumption and cigarette smoking cannot be neglected as factors associated [4]. The management of stroke remains a serious problem for professional healthcare in most African centers because of time delay and lack of neuro-imaging facilities [5]. In recent years elsewhere, studies concerning prognosis of ischemic stroke has been done. The data on admission concerning clinical, biological markers of inflammation as C-reactive protein, interleukin and cytokines, and radiological were analyzed [6-10]. Some published studies indicate that Ischemic stroke patients with systemic inflammation exhibit clinically poorer outcome $[7,11,12]$. In rural practice, these biochemical markers may not be always available or are very expensive. The main objective of the present study was designed to investigate easily identifiable clinical, biological data associated with computed tomographic lesion to predict outcome for patients suffering from ischemic stroke.

\section{Materials and Methods}

A total of 104 patients of Bantu ethnicity of Central Africa, aged $>18$ years old, regardless of sex, consecutively admitted to our hospital with clinical diagnosis of stroke and ischemic lesion on computed tomography scan from January 2011 to June 2014 were enrolled in the study. The patients were explored from 1 to 3 days following the onset of symptoms. Patients with time delay admission were excluded. Clinical data as Glasgow coma scale (GCS) and conventional inflammatory biomarkers easily used in a low resource setting such as erythrocyte sedimentation rate (ESR) and white blood cell (WBC) count were collected and recorded with computed tomographic subtypes of ischemic stroke (lacunar hypodense lesion of $\leq 25 \mathrm{~mm}$ diameter or no lacunar $>25 \mathrm{~mm}$ ) including $78 \%$ of middle cerebral artery stroke. The CT examinations were performed with a helicoidally machine ( Hitachi, Eclo, Japan), in the usual way cuts $10 \mathrm{~mm}$ spaced $5 \mathrm{~mm}$ without injection of contrast material. The ERS was evaluated by means of Westergren's tube method, and the WBC count by New-Bawer cell technique. Poor GCS on admission was defined as 3-8 of a top score of 15 .

\section{Statistical Analysis}

The statistical analysis was performed using commercially available software (SPSS version 21). Univariate analysis with the chi-squared test and the Student's t-test were applied to analyze the statistical significance difference between two groups of patients who died and those who survived. A probability value of $\mathrm{P}<0.05$ was considered as statistically significant difference. Significant variables during univariate

*Corresponding author: Michel Lelo Tshikwela, Department of Radiology, Kinshasa University School of Medicine and Hospital, Kinshasa, Democratic Republic of the Congo, Tel: +243 999907216; E-mail: lelocare60@gmail.com

Received September 19 2015; Accepted October 30, 2015; Published November 06, 2015

Citation: Tshikwela ML, Cinama GB, Tongo SY, Kabu EN, Mbala FK, et al. (2015) Clinical, Biological and Ct Predictors of In-Hospital Mortality in Ischemic Stroke Patients in Central Africa. J Trop Dis 4: 186. doi:10.4172/2329-891X.1000186

Copyright: (c) 2015 Tshikwela ML, et al.This is an open-access article distributed under the terms of the Creative Commons Attribution License, which permits unrestricted use, distribution, and reproduction in any medium, provided the original author and source are credited. 
Citation: Tshikwela ML, Cinama GB, Tongo SY, Kabu EN, Mbala FK, et al. (2015) Clinical, Biological and Ct Predictors of In-Hospital Mortality in Ischemic Stroke Patients in Central Africa. J Trop Dis 4: 186. doi:10.4172/2329-891X.1000186

analysis were subject to multivariate regression in order to identify data independently affecting the in-hospital mortality.

The study was approved by the local research ethics committee.

\section{Results}

Out of the 104 first-ever ischemic stroke patients, 22 (21. 2\%) died. Clinical and biomarker data of the 2 groups of patients (survival vs. died) are presented in (Table 1). Note that the GCS, the ESR, the number of white cell were statistically different in the 2 groups. CT data of the 2 groups are summarized in (Table 2). Parameters associated with mortality in univariate analysis are shown in (Table 3). Parameters associated with mortality on multiple logistic regression analysis are summarized in (Table 4).

\section{Discussion}

The predictors of mortality in the acute phase in patients suffering from ischemic stroke have been attributed to a variety of parameters available in clinical practice. These parameters are: clinical as poor GCS [13-15], biological such as interleukin-1 (IL 1), IL 6, tumor necrosis factor (TNF), fibrinogen, $\mathrm{C}$ reactive protein (CRP), Hematocrit and ESR [7 -12] and radiological as size and site of lesion [16,17]. In this study carried out in an urban setting of Central Africa, the GCS was 10 \pm 2.4 in died patients and was significaly lower compared to survival patients with $12 \pm 2.2$ ( $\mathrm{p}=0.01)$. On univariate analysis, poor GCS was associated with mortality $(\mathrm{p}=0.001)$ but it wasn't seen on multiple logistic regression analysis. Low Glasgow score has been reported by

\begin{tabular}{|l|l|l|l|}
\hline Variables & Died & Survived & p \\
\hline Age (years old) & $65 \pm 13$ & $61 \pm 15$ & 0.295 \\
\hline Poor GCS & $10 \pm 2.4$ & $12 \pm 2.2$ & 0.01 \\
\hline ESR (mm/1H) & $64 \pm 24$ & $38 \pm 30$ & 0.001 \\
\hline WBC count (cell/mm3) & $10.813 \pm 3.228$ & $7.564 \pm 3.823$ & 0.0001 \\
\hline Neutrophils (\%) & $70 \pm 12$ & $64 \pm 11$ & 0.02 \\
\hline
\end{tabular}

Table 1: Summary of clinical and biological data

\begin{tabular}{|l|l|l|l|}
\hline & Died & Survived & p \\
\hline Lacunar infarct & $7 / 31.8$ & $26 / 31.7$ & 0.651 \\
\hline Non lacunar infarct & $20 / 90.9$ & $52 / 63.4$ & 0.04 \\
\hline Middle cerebral artery stroke & $17 / 77.3$ & $51 / 62.2$ & 0.399 \\
\hline
\end{tabular}

Table2: Computed tomographic subtypes of ischemic stroke

\begin{tabular}{|l|l|l|l|}
\hline & OR & $\mathbf{9 5} \% \mathbf{C I}$ & $\mathbf{p}$ \\
\hline Poor GCS & 11.2 & $2.76-45.59$ & 0.001 \\
\hline ESR $\geq \mathrm{mm} / \mathrm{H}$ & 13.7 & $1.97-97.72$ & 0.0001 \\
\hline WBC $\geq 10.000 / \mathrm{mm} 2$ & 3.3 & $1.58-6.68$ & 0.002 \\
\hline Non lacunar infarct & 4.4 & $1.10-17.89$ & 0.003 \\
\hline Hemorrhagic infarct & 3.9 & $2.08-7.52$ & 0.003 \\
\hline Infratentorial infact & 2.7 & $1.35-5.52$ & 0.01 \\
\hline
\end{tabular}

Table 3: Variables associated with mortality in univariate analysis

\begin{tabular}{|l|l|l|l|}
\hline & OR & $\mathbf{9 5 \%} \mathbf{C l}$ & $\mathbf{p}$ \\
\hline Raised erythrocyte sedimentation rate & 1.8 & 1.22 to 89.35 & 0.032 \\
\hline Lesion located in infra-tentorial area & 4.7 & 1.30 to 16.38 & 0.017 \\
\hline Hemorrhagic infarct & 10.6 & 2.21 to 77.89 & 0.005 \\
\hline
\end{tabular}

Table 4: Parameters associated with mortality on multiple analysis
African authors as a clinical factor associated with mortality in patients suffering from stroke $[14,15,18,19]$ and by others $[20,21]$. The ESR, a cellular response to ischemic stroke was found higher $(64 \pm 24 \mathrm{~mm} / \mathrm{h})$ in died patient from acute cerebral infarction $(\mathrm{p}=0.001)$.

Interestingly, ERS was strongly associated with mortality on univariate and multivariate analysis. In 1995 in Italy, the work of Chamorro et al., and in 2004 in Poland by Zaremba et al. reported higher ESR values related to severity of clinical manifestations, greater volume of infarct, and worse outcome after a short time of follow-up [22,23]. More recently in 2012, Kissaliou et al. in Italy shown that high ESR value is associated with larger infarct size [24]. The higher ESR values in the acute phase of ischemic stroke may be expected from elevated plasma levels of acute phase proteins, including CRP and fibrinogen $[25,26]$. This suggests that ERS, a routine test, may be used to predict outcome in low setting area. It is a simple and a non-specific screening test that indirectly measures the presence of inflammation in the body [27] and as known, systemic inflammation exhibit clinically poorer outcomes [9-12,22-24]. The main advantage of ESR over other biomarkers of inflammation is that it is a simple and inexpensive test for assessing an inflammatory or acute response [27] that can be done in any rural hospital. WBC count was $10.813 \pm 3.288 \mathrm{cell} / \mathrm{mm}^{3}$ in patient who died compared to $7.564 \pm 3.823$ found in survival patient and the difference was significant and associated with mortality on univariate analysis but not on multiple logistic regression analysis.

Studies concerning WBC count and mortality in patients suffering from acute ischemic stroke are conflicting. In 2004, Brown et al. in USA [28] and Kanmiersky et al. in Dutch [29] found a relationship between high WBC count on admission and in-hospital mortality in patients with acute ischemic stroke. Recently in 2011, the work of Peng et al. [30] in China, showed an associated relation of increased WBC count with mortality. As in our previous study [31], this findings confirm and support the researches by others. The study of Farah et al. reported that WBC count didnot show and any important prognostic value with in-hospital mortality [32] and were in opposition with ours. As suggested by these authors, the discrepancy may be justified by the variability of etiopathological mechanisms underlying ischemic stroke, atherosclerotic or not in different population study. The increased count of WBC in ischemic stroke patient may be explained by the increased number of lymphocytes particularly the Neutrophils in the blood as the immune cell response originates from the spleen in case of aggression such as ischemic brain ischemia [33]. In this study conducted at Kinshasa, non-lacunar lesions on CT were more seen in died patient compared with survival and this was statistically different $(\mathrm{p}=0.04)$. Large ischemic stroke with progressive edema development is frequently life-threatening and associated with a poor prognosis due to limited expandability within the cranial cavity [34]. Some studies on small vessel cerebrovascular disease suggested that lacunar infarct have been associated with a favorable short-term prognosis [35,36]. In our series, infratentorial ischemic lesion was a parameter associated with mortality on multiple analyses. Swelling of a large space-occupying cerebellar infarct appears within a few days from symptom onset and can lead to compression of the brainstem and midbrain or cause a hydrocephalus [34].

Finally, hemorrhagic transformation of acute ischemic stroke was more seen in dead patient on univariate and multivariate analysis (OR10.6 95\%IC 2.21 to 77.89 and $\mathrm{p}>0.005$ ). Acute ischemic stroke is already a devastating disease that is further complicated by hemorrhagic transformation [37]. Hemorrhagic transformation may be spontaneous or a complication of intravenous thrombolysis treatment that is associated with high mortality [38]. 
Citation: Tshikwela ML, Cinama GB, Tongo SY, Kabu EN, Mbala FK, et al. (2015) Clinical, Biological and Ct Predictors of In-Hospital Mortality in Ischemic Stroke Patients in Central Africa. J Trop Dis 4: 186. doi:10.4172/2329-891X.1000186

\section{Limitations of the study and Future research directions}

In this study conducted in a tropical area, first, common causes of inflammation increasing ESR and WBC count as infectious diseases were not excluded. Second, the systemic inflammatory status prior to the time of stroke onset was not assessed and Rong suggest that this status is a key determinant of acute outcome and long-term prognosis [11]. Third, the volume of ischemic lesion known as associated with a poor prognosis was not measured. For future study, each of these biases should be taken into consideration to allow an estimate of the significance and robustness of the findings under tropical climate. However, this study accesses the highlights of clinical and easy biomarkers using CT scan explorations. It may have an important clinical implication suggesting the use of Siriraj and GCS with routine biomarkers of inflammation to predict outcome in the management of patients suffering from this "bad" [3], dramatic and live-threatening disease in rural practice.

\section{Conclusion}

This study conducted in Central Africa settings revealed simple determinants associated with mortality in ischemic stroke as poor GCS and routine biomarkers levels especially ESR and WBC count. Given some limitations of the present study, investigations are warranted to confirm the present suggestion in African lack neuro-imaging facilities centers.

\section{References}

1. Di Carlo A (2009) Human and economic burden of stroke. Age Ageing 38: 4-5.

2. Feigin VL, Forouzanfar $M H$, Krishnamurthi R, Mensah GA, Connor M, et al. (2014) Global and regional burden of stroke during 1990-2010: findings from the Global Burden of Disease Study 2010. Lancet 383: 245-254.

3. Greenberg SM (2007) Intracerebral Hemorrhage: Introduction. Stroke 38: 746747 .

4. Tshikwela ML, Londa FB, Tongo SY (2015) Stroke subtypes and factors associated with ischemic stroke in Kinshasa, Central Africa. Afr Health Sci 15: 68-73.

5. Ogun SA (2002) Management of ischemic stroke - Recent advances. Nigerian journal of clinical Practice 5: 130-138.

6. Elkind MSV (2010) Princeton Proceedings: Inflammatory mechanism of stroke. Stroke 41: 53-58.

7. Muhammed KS, Pirbhomal M, Zulfiqar AQB, Muhammad FM, Bikha RD, et al. (2011) C-Reactive Protein in Patients with Ischemic Stroke. World Applied Sciences Journal 15: 1220-1224.

8. Longo-Mbenza B, Phanzu-Mbete LB, M'Buyamba-Kabangu JR, Tonduangu K Mvunzu M, et al. (1999) Hematocrit and stroke in black Africans under tropical climate and meteorological influence. Ann Med Interne (Paris) 150: 171-177.

9. Celikbilek A, Ismailogullari S, Zararsiz G (2014) Neutrophil to lymphocyte ratio predicts poor prognosis in ischemic cerebrovascular disease. J Clin Lab Anal 28: 27-31.

10. Elkind MS, Luna JM, McClure LA, Zhang Y, Coffey CS, et al. (2014) C-Reactive Protein as prognostic marker after lacunar stroke: Levels of inflammatory markers in the treatment of stroke study. Stroke 45: 707-716.

11. Jin R, Liu L, Zhang S, Nanda A, Li G (2013) Role of inflammation and its mediators in acute ischemic stroke. J Cardiovasc Transl Res 6: 834-851.

12. Worthmann H, Tryc AB, Goldbecker A, Ma YT, Tountopoulou A, et al. (2010) The temporal profile of inflammatory markers and mediators in blood after acute ischemic stroke differs depending on stroke outcome. Cerebrovasc Dis 30: 85-92.

13. Sato S, Uehara T, Ohara T, Suzuki R, Toyoda K, et al. (2014) Factors associated with unfavorable outcome in minor ischemic stroke. Neurology 83: 174-181.

14. Ekeh B, Ogunniyi A, Isamade E, Ekrikpo U (2015) Stroke mortality and its predictors in a Nigerian teaching hospital. Afr Health Sci 15: 74-81.

15. Owolabi LF, Mohammed AD, Dalhat MM, Ibrahim A, Aliyu S, et al. (2013) Factors associated with death and predictors of 1-month mortality in nontraumatic coma in a tertiary hospital in Northwestern Nigeria. Indian J Crit Care Med 17 219-223.

16. Pexman JH, Barber PA, Hill MD, Sevick RJ, Demchuk AM, et al. (2001) Use of the Alberta Stroke Program Early CT Score (ASPECTS) for assessing CT scans in patients with acute stroke. AJNR Am J Neuroradiol 22: 1534-1542.

17. Miyamoto N, Tanaka Y, Ueno Y, Kawamura M, Shimada Y, et al. (2013) Demographic, clinical, and radiologic predictors of neurologic deterioration in patients with acute ischemic stroke. J Stroke Cerebrovasc Dis 22: 205-210.

18. Tambwe M, Mbala M, Lusamba DN, M'buyamba-Kabangu JR (1995) Morbidity and mortality in hospitalised Zairean adults. S Afr Med J 85: 74

19. M'Buyamba-Kabangu JR, Longo-Mbenza B, Tambwe MJ, Dikassa LN, MbalaMukendi M (1995) J-shaped relationship between mortality and admission blood pressure in black patients with acute stroke. J Hypertens 13: 1863-1868.

20. Alonso A, Ebert AD, Kern R, Rapp S, Hennerici MG, et al. (2015) Outcome Predictors of Acute Stroke Patients in Need of Intensive Care Treatment. Cerebrovasc Dis 40: 10-17.

21. Horsting MW, Franken MD, Meulenbelt J, van Klei WA, de Lange DW (2015) The etiology and outcome of non-traumatic coma in critical care: a systematic review. BMC Anesthesiol 15: 65.

22. Chamorro A, Vila N, Ascaso C, Saiz A, Montalvo J, et al. (1995) Early prediction of stroke severity. Role of the erythrocyte sedimentation rate. Stroke 26: 573576.

23. Zaremba J, Skrobański P, Losy J (2004) Acute ischaemic stroke increases the erythrocyte sedimentation rate, which correlates with early brain damage. Folia Morphol (Warsz) 63: 373-376

24. Kisialiou A, Pelone G, Carrizzo A, Grillea G, Trimarco V, et al. (2012) Blood biomarkers role in acute ischemic stroke patients: higher is worse or better? Immunity \& Ageing 9: 22

25. Di Napoli M (2001) Early inflammatory response in ischemic stroke. Thromb Res 103: 261-264.

26. Emsley HC, Smith CJ, Gavin CM, Georgiou RF, Vail A, et al. (2003) An early and sustained peripheral inflammatory response in acute ischaemic stroke: relationships with infection and atherosclerosis. J Neuroimmunol 139: 93-101.

27. Ranga GS (2014) Commentary. J Neurosci Rural Pract 5: 45-46.

28. Brown DW, Ford ES, Giles WH, Croft JB, Balluz LS, et al. (2004) Associations between white blood cell count and risk for cerebrovascular disease mortality: NHANES II Mortality Study, 1976-1992. Ann Epidemiol 14: 425-430.

29. Kazmierski R, Guzik P, Ambrosius W, Ciesielska A, Moskal J, et al. (2004) Predictive value of white blood cell count on admission for in-hospital mortality in acute stroke patients. Clin Neurol Neurosurg 107: 38-43.

30. Peng Y, Wang D, Zhang J, Xue X, Wang Z, et al. (2011) Relationship between white blood cell count at admission and short term outcome in patients with acute cerebral infarction. Clin Invest Med 34: E249.

31. Longo-Mbenza B, Lelo Tshinkwela M, Mbuilu Pukuta J (2008) Rates and predictors of stroke-associated case fatality in black Central African patients. Cardiovasc J Afr 19: 72-76

32. Farhad I, Nazanin Zia-S, Alireza V, Ahmadreza S (2014) Relationship between White Blood Cell Count and Mortality in Patients with Acute Ischemic Stroke. ZJRMS 16: 16-19.

33. Leuschner F, Panizzi P, Chico-Calero I, Lee WW, Ueno T, et al. (2010) Angiotensin-converting enzyme inhibition prevents the release of monocytes from their splenic reservoir in mice with myocardial infarction. Circ Res 107 1364-1373.

34. Bösel J, Schwab S, Kollmar R (2012) Space-occupying supratentorial and infratentorial ischemic stroke. Stroke syndrome 3rd edn. Cambridge University Press.

35. Fisher CM (1968) The arterial lesions underlying lacunes. Acta Neuropathol 12: $1-15$.

36. Behrouz R, Malek AR, Torbey MT (2012) Small vessel cerebrovascular disease: the past, present, and future. Stroke Res Treat 2012: 839151. 
Citation: Tshikwela ML, Cinama GB, Tongo SY, Kabu EN, Mbala FK, et al. (2015) Clinical, Biological and Ct Predictors of In-Hospital Mortality in Ischemic Stroke Patients in Central Africa. J Trop Dis 4: 186. doi:10.4172/2329-891X.1000186

Page 4 of 4

37. Sussman ES, Connolly ES Jr (2013) Hemorrhagic transformation: a review of the rate of hemorrhage in the major clinical trials of acute ischemic stroke. Front Neurol 4: 69
38. Miller DJ, Simpson JR, Silver B (2011) Safety of thrombolysis in acute ischemic stroke: a review of complications, risk factors, and newer technologies. Neurohospitalist 1: 138-147. 